Cite this: Mol. BioSyst., 2014 10, 1255

Received 29th July 2013,

Accepted 18th October 2013

DOI: $10.1039 / \mathrm{c} 3 \mathrm{mb} 70316 \mathrm{a}$

www.rsc.org/molecularbiosystems

\section{Antineoplastic activity of strawberry (Fragaria $\times$ ananassa Duch.) crude extracts on B16-F10 melanoma cells}

\author{
Cinzia Forni, ${ }^{\star a}$ Roberto Braglia, ${ }^{a}$ Nadia Mulinacci, ${ }^{\mathrm{b}}$ Andrea Urbani, ${ }^{\mathrm{c}}$ \\ Maurizio Ronci, ${ }^{\mathrm{cd}}$ Angelo Gismondi, ${ }^{\mathrm{a}}$ Claudio Tabolacci, ${ }^{\mathrm{a}}$ Bruno Provenzano, ${ }^{\mathrm{a}}$ \\ Alessandro Lentini ${ }^{a}$ and Simone Beninati ${ }^{a}$
}

\begin{abstract}
The antiproliferative and differentiation potential of anthocyanin-rich strawberry fruit crude extracts (SE) were investigated on B16-F10 murine melanoma cells. Treatment of melanoma cells with SE produced a remarkable reduction of cell proliferation, paralleled with both the lowering of the intracellular levels of polyamine, and the enhancement of tissue transglutaminase (TG2, EC 2.3.2.13) activity (used as a differentiation marker). To gain further insight into profiling altered protein expression as a potential biomarker of the SE action on melanoma cells, analysis of the proteomic profile was performed on the treated B16-F10 cells, compared to the control. Following SE treatment, 30 proteins resulted up-regulated, and 87 proteins were down-regulated. In particular proteins overexpressed in cancer cells, involved in tumor progression and metabolism, were down-regulated. The possibility that SE may affect the Warburg effect in B16-F10 melanoma cells is discussed.
\end{abstract}

\section{Introduction}

Epidemiological studies suggest that the consumption of phytochemical-rich food, which includes fruits and vegetables, contributes to the reduction of the risk of certain types of human cancers. ${ }^{1}$ Berries such as blackberry (Rubus sp.), blueberry (Vaccinium corymbosum L.) and strawberry (Fragaria $\times$ ananassa Duch.) are popularly consumed in a human diet in fresh and in processed forms such as beverages, yogurts, jellies and jams. In addition, berry extracts are widely consumed in botanical dietary supplement forms for their potential human health benefits. ${ }^{2-5}$ Accordingly, there has been a focus on identifying components of fruits and vegetables responsible for anticancer effects. ${ }^{6}$ Berries contain a complex mixture of antioxidants including vitamin C, carotenoids, xanthophylls and polyphenols, which differ in a species-specific manner. ${ }^{7}$ Individual polyphenols, such as flavonoids, have been shown to inhibit cancer cell proliferation. ${ }^{8,9}$ Flavonoids

\footnotetext{
${ }^{a}$ Department of Biology, University of Rome "Tor Vergata", Via della Ricerca Scientifica, 00133 Rome, Italy.E-mail: forni@uniroma2.it; Fax: +39 062023500; Tel: +390672594345

${ }^{b}$ Department of Neurosciences, Psychology, Drug Research and Child Health, Division of Pharmaceutical and Nutraceutical Sciences and Multidisciplinary Centre of Research on Food Sciences (M.C.R.F.S.-Ce.R.A.), University of Florence, Sesto Fiorentino, Florence, Italy

${ }^{c}$ European Brain Research Institute (EBRI), IRCCS Fondazione Santa Lucia, Rome, Italy

${ }^{d}$ Mawson Institute, University of South Australia, Mawson Lakes SA 5095, Australia
}

are the most widely represented class of phenolic compounds in strawberry receptacle ${ }^{5}$ and, among them, anthocyanins are quantitatively the most important type, with some qualitative and quantitative variations within the cultivars. ${ }^{3,10}$

In this work, we report the antitumor activities of an anthocyanin-rich strawberry extract (SE) on the highly metastatic B16-F10 murine melanoma cell line. The SE was obtained from fruits of the cultivar Pajaro and its composition was characterized by HPLC/DAD/MS. In order to collect evidence on the potential antineoplastic activity, the possible induction of tumor cell differentiation by the SE, as well as the antiproliferative effect, have been investigated. The activity of tissue transglutaminase (TG2; E.C. 2.3.2.13) has been used as a differentiation marker and the intracellular polyamine levels have been used as proliferation markers. ${ }^{11}$ Transglutaminases belong to a class of enzymes which catalyzes the post-translational modification of proteins by the formation of isopeptide bonds. $^{12,13}$ There is increasing evidence of direct correlation between TG2 activation and reduction of cancer progression, by means of stimulation of tumor cell differentiation. The linkage between the TG2-dependent antineoplastic activity and the induction of cell differentiation as well as the involvement of the enzyme in the metastatic spread is well defined in melanoma cells lines. ${ }^{14}$ It is also well known that, after intracellular activation, soluble TG2 may cross-link proteins, leading to the formation of envelopes in apoptotic cells, while extracellular activation contributes to the stabilization of the extracellular matrix (ECM) and 
promotes cell-substrate interactions. ${ }^{15}$ Transglutaminases can catalyze also the covalent incorporation of several low molecular weight amines into proteins in the form of amides of the $\gamma$-carboxyl group of a peptide-bound glutamic acid. During cell differentiation, polyamines (POL), such as putrescine (PUT), spermidine (SPD) and spermine (SPM), may be covalently conjugated to glutaminyl residues of polypeptides through a transamidation reaction catalyzed by TG2. ${ }^{12}$ As a consequence of POL deficiency, cell proliferation can be stopped, driving cells to apoptosis.

We investigated also the response of two tumor markers: p53, probably the most common target for genetic alterations in cancer, known to induce cell cycle arrest, apoptosis or differentiation of potentially malignant cells ${ }^{16,17}$ and $\mathrm{p} 21$, a transcriptional target of p53, able to arrest the cell cycle in the $\mathrm{G}_{1}$ phase, whose expression is related to the induction of differentiation in a variety of tissues. ${ }^{18}$ Moreover, the proteomic approach was used to investigate changes in protein patterns following cell treatment with SE.

\section{Results}

\section{Composition of strawberry extracts (SE)}

The extraction was mainly focused to recover the anthocyanin fraction, therefore an acidic and polar mixture was used. The concentration of total phenols, determined by the Folin-Ciocalteau method, was $22.6 \pm 0.2 \mathrm{mg} \mathrm{g}^{-1}$ fresh weight, and the anthocyanin fraction, evaluated by HPLC/DAD, was $333.0 \pm 6.6 \mu \mathrm{g} \mathrm{g}{ }^{-1}$ fresh weight. The HPLC analyses (Fig. 1) allowed the detection, in agreement with other authors, ${ }^{19,20}$ of three anthocyanins: cyanidin 3-O-glucoside and pelargonidin 3-O-rutinoside as minor pigments, and pelargonidin 3 -O-glucoside as a main constituent. Among these pigments, the glycosides of pelargonidin constituted the $95 \%$ of the anthocyanin fraction. The co-presence of a glucose ester of $p$-coumaric acid $\left(39.7 \pm 1.19 \mu \mathrm{g} \mathrm{g}^{-1}\right.$ fresh weight) and of its analogue was also detected. ${ }^{21}$ The UV-vis and mass spectra, together with the literature data, ${ }^{19-21}$ were determinant to recognize the phenolic compounds of this extract. The mass detector in positive ionization mode was applied to confirm the anthocyanins, present as ion species in the acidic medium. Their mass spectra showed the molecular ion $[\mathrm{M}]^{+}$of the glycosidic forms and the ion species related to the aglycons (cyanidin at $\mathrm{m} / \mathrm{z}$ 287 and pelargonidin at $m / z 271$ ). More informative mass spectra of the other phenols listed in Fig. 1 were achieved in negative ionization mode, and were characterized by the presence of the pseudo molecular ion $[\mathrm{M}-\mathrm{H}]^{-}$and the species derived by the loss of the glycosidic group (162 amu). The EI profile related to $325 \mathrm{~m} / \mathrm{z}$, the pseudo-molecular ion of the isobaric compounds $\mathbf{1}$ and 2, is shown in Fig. 1c. The ellagic acid, a typical compound of the strawberry fruit, was not present in our sample as confirmed by the

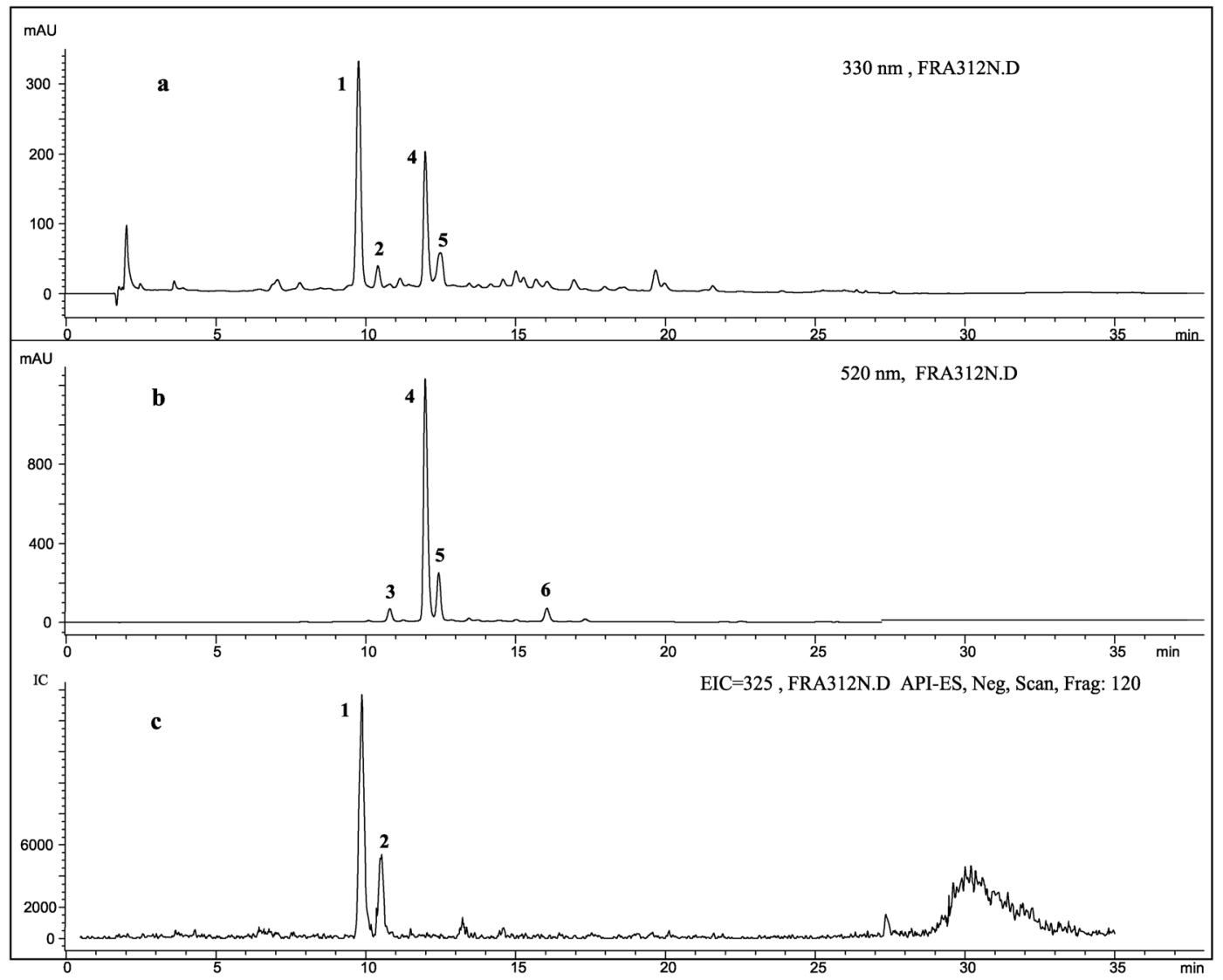

Fig. 1 Chromatographic profiles of strawberry extracts (cv. Pajaro) at $330 \mathrm{~nm}$ (a); at $520 \mathrm{~nm}$ (b) to highlight the anthocyanins, and the Extract lon profile at $325 \mathrm{~m} / \mathrm{z}$ (c) of the cumaroyl monoglycosides. (1) p-Cumaroyl monohexose; (2) cumaroyl monoglucoside; (3) cyanidin 3-O-glucoside; (4) pelargonidin 3-O-glucoside; (5) pelargonidin 3-O-rutinoside; (6) pelargonidin 3-O-acylglucoside. 
analyses of the UV-Vis spectra, and the comparison with the pure standard, applying the EI technique on the TIC of the SE obtained in negative ionization mode. This result is in agreement with the partial lipophilicity of ellagic acid and with the selected extraction method specifically targeted to recover the polar anthocyanin fraction.

\section{Inhibition of cancer cell proliferation and reduction of intracellular polyamine levels}

Treatment of B16-F10 melanoma cells with SE affected cell proliferation, in fact the treatment reduced cell growth by about $30 \%$ after $48 \mathrm{~h}$ and by about $27 \%$ after $72 \mathrm{~h}$ (Fig. 2). Treatment did not cause cell injury and had a toxicity lower than $5 \%$, as assayed by the Trypan Blue exclusion test (data not shown). Intracellular concentration of POL was determined after 24, 48 and $72 \mathrm{~h}$ of SE treatment. PUT was detected only in traces in all samples. After $48 \mathrm{~h}$ of treatment, the SPD amount decreased to $47.2 \%$ (Fig. 3), while SPM content was $20.7 \%$ lower than the control. After $72 \mathrm{~h}$ of incubation with SE, a further decrease of SPD (63.8\%) and SPM (52.9\%) levels was detected.

\section{Effect of SE on transglutaminase activity}

Transglutaminase activity determination represents one of the methods to evaluate cell differentiation, since it is considered a differentiative biomarker. We checked in the B16-F10 melanoma cell line the possible effect of SE on the modulation of this marker, and the results are shown in Fig. 4. Twenty-four-hour incubation of B16 cells with SE did not affect the enzyme activity, compared to the control. On the other hand, treatment with SE significantly induced, compared to the control, an enhancement in TG2 activity after $48 \mathrm{~h}$ ( $172 \%$ increase) and after $72 \mathrm{~h}$ ( $35 \%$ increase).

\section{Down regulation of p53 and p21}

p53 and p21 expression were determined in B16-F10 melanoma cells treated with SE (Fig. 5). Western blot analysis was

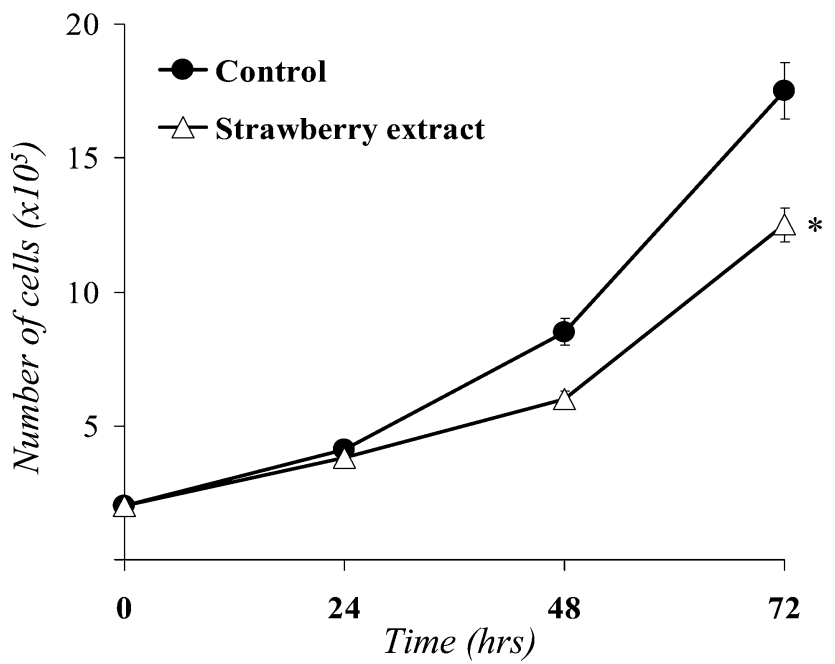

Fig. 2 Antiproliferative effect of the strawberry extract on B16-F10 melanoma cells. Data are expressed as the mean \pm SD of three different determinations; $* p<0.05$, compared to the control.

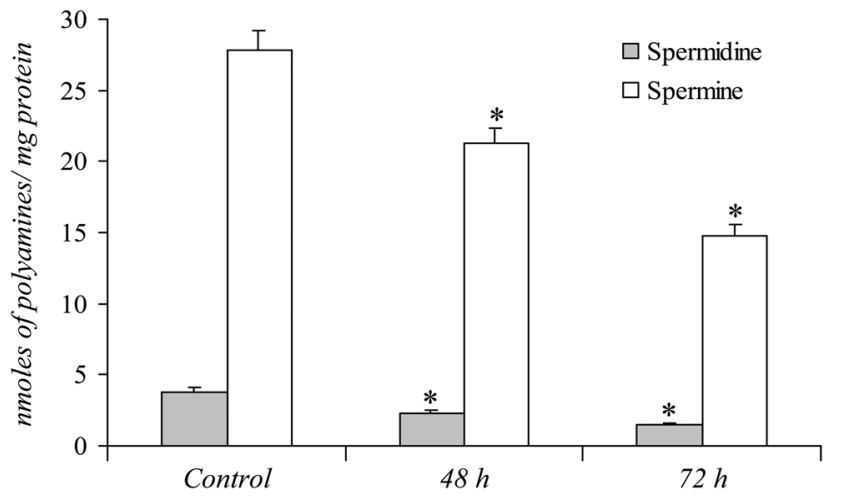

Fig. 3 Polyamine concentration in B16-F10 melanoma cells treated with strawberry extracts. The concentration of putrescine was lower than the limit of quantification for the used analytical method. Each point represents the mean of three different determinations \pm SD $\left({ }^{*} p<0.05\right)$.

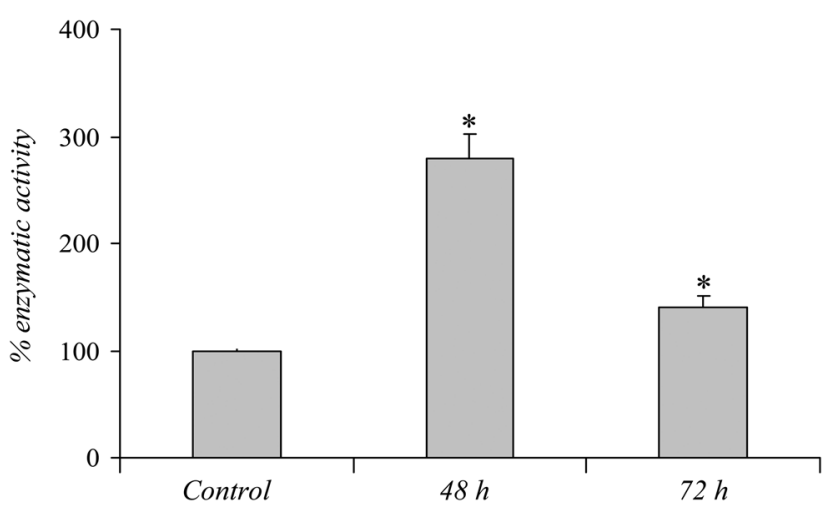

Fig. 4 Effect of strawberry extracts on tissue transglutaminase activity in B16-F10 melanoma cells. Data are expressed as the mean \pm SD of three different determinations; ${ }^{*} p<0.05$, compared to the control.
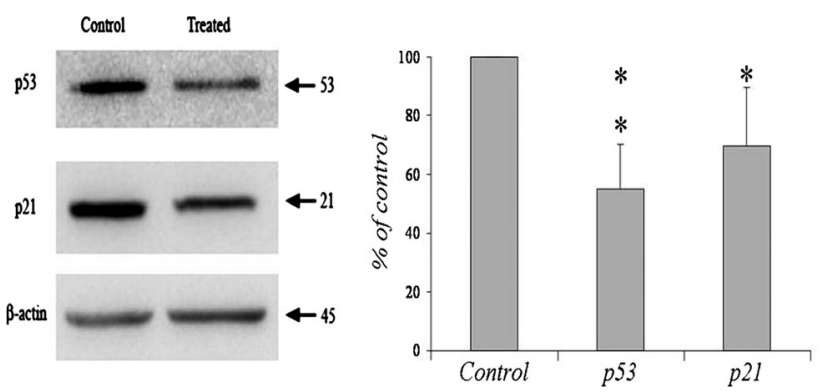

Fig. 5 Effects of strawberry extracts on the expression levels of the proteins $\mathrm{p} 53$ and $\mathrm{p} 21$ in B16-F10 melanoma cells. Total cell lysates were prepared after $48 \mathrm{~h}$ of treatment and Western blot was performed using antibodies specific for p53, p21 and $\beta$-actin. ${ }^{*} p<0.05$, ** $p<0.001$ compared to non-treated control cells.

performed on total cell lysates using antibodies specific to p53, p21 and $\beta$-actin. The levels of p53 and p21 were decreased compared to the control of $47.2 \%$ and $32.6 \%$, respectively.

\section{Protein pattern analysis}

The protein pattern was analysed in triplicate by two-dimensional gel electrophoresis (2-DE). An average of 500 protein spots per gel 


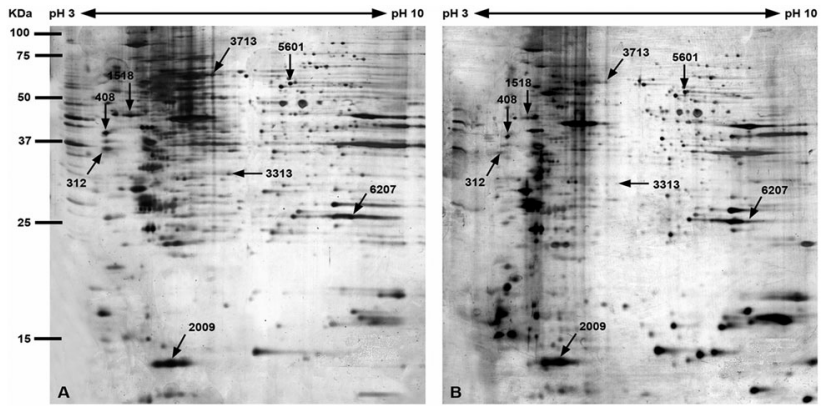

Fig. 6 Representative 2-D gels of total extracts from B16-F10 melanoma cells untreated (panel A) and treated with strawberry extracts (panel B). Spots labelled with numbers indicate the most interesting proteins that were found to be significantly modified after treatment.

were detected (Fig. 6). Protein synthesis in SE treated B16-F10 cells was clearly affected according to the comparison of 2D patterns of untreated (Fig. 6A) and treated cells (Fig. 6B). The expression of 121 proteins resulted significantly different. In particular, 87 proteins resulted down-regulated and 30 up-regulated. Moreover, four proteins were detected only in treated-melanoma cells. Out of a total of 20 spots excised from the gels, 8 spots yielded a good MALDI spectra. Peptide mass fingerprinting allowed the identification of these proteins (Table 1).

\section{Discussion}

Oxidative stress induces a cellular redox imbalance, typical of various cancer cells, and related to oncogenic stimulation. The permanent modification of genetic material resulting from "oxidative damage" represents the first step of mutagenesis, carcinogenesis and ageing. An important role in maintaining physiological homeostasis is played by diet and nutrition. In fact, recent literature emphasizes the potential therapeutic effect of nutrients found in natural products, indicating positive applications for controlling the pathogenesis of chronic diseases driven by oxidative stress. ${ }^{22}$ Polyphenolic compounds are ubiquitous dietary components and specific polyphenols are very effective in scavenging oxygen and nitrogen reactive species. They are able to modulate genes associated with cell metabolism, stress defence, drug metabolizing enzymes, detoxification and transporter proteins. ${ }^{6}$ Their function is protective in overcoming damaging effects of chronic diseases and in delaying the degenerative ageing. The mechanisms involved in their activities are complex, determined by the structure of the compound, the redox status of the environment and interactions with other agents.

Among edible fruits, strawberry, together with other berries, represents one of the most important sources of bioactive compounds. Their qualitative and quantitative composition depends on genetic and environmental factors affecting the production and accumulation of these molecules in fruits. ${ }^{23}$ The qualitative composition of flavonoids of cv. Pajaro, mainly represented by three anthocyanins, pelargonidin 3-O-glucoside, cyanidin 3 -O-glucoside and pelargonidin 3 -O-rutinoside, is in agreement with those reported by other authors. ${ }^{19,20}$ The presence of a quite abundant amount of glucose ester of $p$-coumaric acid was also detected, this compound can be found in a wide variety of edible plants ${ }^{24}$ as well as berries. ${ }^{19,20}$

Several parameters of melanoma cells were affected by the treatment with strawberry flavonoid extracts: a significant inhibition of cell proliferation in treated B16-F10 cells, associated with a very low cytotoxicity, has been clearly demonstrated. These data were also confirmed by the reduction of the intracellular content of SPD and SPM, well known proliferation markers. The role of pelargonidin glycosides, the main anthocyanin detected in strawberry extracts, as antitumor compounds is still controversial and to be elucidated, since treatment of melanoma cells with the pelargonidin chloride did not affect cell proliferation. ${ }^{8}$ At the moment, two hypotheses may be put forward, i.e. pelargonidin glycosides contained in the fruit extract may exert an anticancer role by acting in synergy with other active components, or the antiproliferative effect of the extract is not due to these pigments, but to other co-present compounds. The second hypothesis is supported by data for the inhibitory effects of cyanidin 3-rutinoside and cyaniding 3-glucoside from Morus alba on the invasion and motility of A549 cells. $^{25}$ Besides cyanidin 3-O-glucoside, another component of the extract may play an important role in determining the antitumor effect. This molecule, present usually as an ester of quinic acid, sterol, or glucose, has been considered as an anti-inflammatory, antioxidant, and antimicrobial agent as well as anticarcinogenic. ${ }^{26,27}$ Moreover, as reported by Ferguson and colleagues, ${ }^{28} p$-coumaric acid reduces the risk of stomach cancer probably by reducing the formation of carcinogenic nitrosamines. $^{29}$

Table 1 Differentially expressed proteins in untreated and treated B16-F10 cells identified by MALDI-TOF MS

\begin{tabular}{llllll}
\hline No & $\begin{array}{l}\text { Theoretical } \\
\text { Mr (Kda) }\end{array}$ & $\begin{array}{l}\text { Experimental } \\
\text { Mr (Kda) }\end{array}$ & $\begin{array}{l}\text { Average ratio } \\
\text { untreated/treated } \pm \text { SD }\end{array}$ & $\begin{array}{l}\text { SWISS-PROT/ } \\
\text { Tremble acc. number }\end{array}$ & Description \\
\hline 0408 & 33.4 & 38 & $3.72 \pm 0.56$ & Q9EQU5 & Protein SET \\
0312 & 38 & 35.9 & $2.88 \pm 0.08$ & P70670 & Nascent polypeptide-associated complex subunit alpha \\
2009 & 14 & 14 & $2.29 \pm 0.18$ & P16045 \\
3713 & 57.8 & 65 & $5.70 \pm 0.23$ & P52480 & Galectin-1 \\
5601 & 56.6 & 53.5 & $2.17 \pm 0.09$ & Q61753 & Pyruvate kinase isozymes M1/M2 \\
6207 & 26.7 & 25 & $1.49 \pm 0.54$ & P17751 & D-3-phosphoglycerate dehydrogenase \\
1518 & 42.7 & 44 & $2.56 \pm 0.17$ & Q04447 & Triosephosphate isomerase \\
3313 & 29.5 & 35.2 & $20.6 \pm 1.89$ & P61290 & Protine kinase B-type
\end{tabular}

Experimental Mr was estimated using PDQuest software. The ratio as the mean \pm SD of three experiments both for untreated and treated cells cultured for $48 \mathrm{~h}$ under similar conditions. 
Among the human genome, p53 is one of the first tumor suppressor genes to be discovered. It has a wide range of functions covering cell cycle control, apoptosis, genome integrity maintenance, metabolism, fertility, cellular reprogramming and autophagy. ${ }^{30}$ The observation of the decrease of p53 levels and the induction of the transamidating activity of TG2, after SE treatment, suggests a possible induction of tumor cell differentiation without DNA damages. Similar results have been reported in F9 cells induced to differentiate in vitro ${ }^{31}$ and in epidermal keratinocytes that showed a decline in p53 protein in conjunction with terminal differentiation. $^{32}$ Then, recent studies suggest that TG2 plays an active role in the response of neuroblastoma cells to DNA-damage-induced stress, by exerting a strong protective effect, likely by the suppression of p53 activation and p53-driven cell signaling events. ${ }^{33}$ Anyway, it is also known that TG2, which possess a kinase activity, is able to phosphorylate $\mathrm{p} 53$. This event may facilitate apoptosis, by disrupting the interaction of $\mathrm{p} 53$ with $\mathrm{Mdm} 2$, thereby preventing the subsequent degradation and allowing p53 accumulation. ${ }^{34}$ Under this view, the interplay between TG2 and p53 in melanoma cells requires further investigation. Similarly, p21 protein levels decreased after SE treatment, evidence already shown for cells which express low levels of p53. ${ }^{35,36}$

The effect of the extract on cell proteome was really relevant, many proteins were up- or down-regulated. We were able to identify 8 out of these differentially expressed proteins. Three of the down regulated proteins, galectin-1 (GAL-1), proteasome activator complex subunit 3 (REG-gamma), creatine kinase B-type (CKB), are involved in the promotion of the metastatic process. According to the literature, it is reasonable to assume that GAL-1 expression or overexpression in a tumor or tissue surrounding a tumor (stroma) can be considered a sign of the tumor malignant progression. ${ }^{37}$ In particular, the metastatic cascade is a multistep process including cell-cell interaction, cell-ECM adhesion, invasion, migration and angiogenesis. GAL-1 is involved in many of these steps. ${ }^{38}$ GAL- 1 is also implicated in the mechanisms of tumor immune-escape: tumors can evade immune responses by secreting immunosuppressive cytokines and soluble inhibitory factors, including GAL-1. This protein also contributes to immune evasion inducing apoptosis in effector $\mathrm{T}$ cells. ${ }^{39,40}$ A role in the immune response is well known for proteasome. In particular, proteasome inhibitors affect the immune response by repressing antigen presentation on major histocompatibility complex class I (MHC-I) receptors, ${ }^{41}$ by suppressing cytokine secretion, cell-cell-interaction, migration and chemotaxis of lymphocytes and by inducing apoptosis in activated T-cells. Proteasomes are responsible for the degradation of cellular proteins in eukaryotic cells, and they play an important role in cell cycle progression, apoptosis, angiogenesis and drug resistance. Since these pathways are fundamental for cell survival and proliferation, particularly in cancer cells, the inhibition of proteasomes is an attractive potential anti-cancer therapy. ${ }^{42}$ REG-gamma is a member of the proteasome activator complex (PA28) family, which has been shown to bind specifically to $20 \mathrm{~S}$ proteasomes and greatly stimulate the hydrolysis of peptides, hence REG-gamma is an anti-apoptotic factor as it is an endogenous substrate for caspase-3 and caspase- 7 .
Thus, downregulation of REG-gamma may inhibit proteasome functions and induce apoptosis. ${ }^{43,44}$ Moreover the inhibition of the proteasome by anthocyanins and anthocyanidins has already been reported ${ }^{45}$ and it has been demonstrated that proteasomal inhibition helps cytoprotection against oxidative stress by inducing glutathione synthesis. ${ }^{46} \mathrm{CKB}$ expression was commonly increased in the metastatic B16 cell line ${ }^{47}$ and in other ovarian cancer cells. CKB gene expression is up-regulated and the CKB enzyme activity is significantly elevated in sera from ovarian cancer patients, including those with stage I disease ${ }^{48}$ and in serum of lung and colon cancer patients. ${ }^{49}$ Nevertheless current data for creatine content and creatine-kinase expression in malignant cells and tumor-bearing animals are contrasting and that probably depend on the particular tumor model system. ${ }^{50}$

Altered metabolism is one of the hallmarks of cancer cells. The best-known metabolic abnormality in cancer cells is the Warburg effect, which demonstrates an increased glycolysis even in the presence of oxygen. To this point of view, the inhibition of glycolysis induces a decrease in ATP cellular levels, affecting cancer cell growth and proliferation. Thus, the alteration of cancer cell glucose metabolism may represent a novel and promising anticancer strategy. ${ }^{51}$ Two of the down regulated identified proteins, pyruvate kinase M1/M2 and triosephosphate isomerase, are involved in the glycolysis. The latter enzyme is up-regulated in several types of cancer $^{52}$ and according to Wang and colleagues ${ }^{53}$ it may be involved in the chemoresistance. An increase in activity of D-3-phosphoglycerate dehydrogenase (PGDH), a key enzyme in the pathway of synthesis of serine, was reported in human colon carcinoma, rat sarcoma, and rat hepatoma cell lines during the proliferative phase. ${ }^{54}$ Moreover, as previously reported, PDGH may be an attractive drug target in melanoma. ${ }^{55}$ In this work we demonstrated that $\mathrm{SE}$ are able to induce a reduction in PDGH expression.

From a pharmacological point of view, drugs able to perturb cancer cell metabolism at the level of glycolysis or other metabolic pathways ${ }^{56}$ may open a new perspective in cancer treatments, since they may overcome some of the limitations of the molecules currently used in the therapy. ${ }^{57}$

\section{Conclusions}

In conclusion, the results from our study suggest that SE, characterized by a high content of anthocyanins, exert their action mainly through the induction of cell differentiation. However, it is well clear that the serum bioavailability of many berry polyphenols is low $^{58}$ and probably orders of magnitude lower than the levels of berry extracts required for effective inhibition of melanoma cell proliferation in this study. Indeed, it has been reported that bilitranslocase is involved in regulating the function and the permeability of the gastric mucosa, increasing the bioavailability of the anthocyanins. ${ }^{59,60}$

Our studies provide preliminary data for the ability of this extract to inhibit the growth and induce differentiation in a melanoma cancer cell line. Moreover, the synergistic combination of a natural differentiation molecule and a conventional chemotherapeutic agent, which could be therefore administered in 
lower dose, represents an attractive strategy for cancer treatments and it may assume particular importance considering the sensible reduction of the side-effects due to the intrinsic cytotoxicity of the chemotherapeutic agents. ${ }^{61}$ Future studies should be designed to investigate the potential of berries in the prevention and treatment of chronic human diseases such as cancer. Lastly, changes in dietary and/or nutritional patterns might have a profound impact on reducing cancer incidence.

\section{Experimental}

\section{Materials}

Dulbecco's modified Eagle's medium (DMEM), glutamine, penicillin (10000 UI mL $\left.{ }^{-1}\right)$ and streptomycin $\left(10000 \mu \mathrm{g} \mathrm{mL}^{-1}\right)$ were from Eurobio Laboratoires (Le Ulis Cedex, France). Fetal calf serum (FCS) was from Gibco (Grand Island, NY, USA). $\left[{ }^{14} \mathrm{C}\right]$-methylamine $\left(46.6 \mathrm{mCi} \mathrm{mmol}{ }^{-1}\right)$ was purchased from Amersham International (Bucks, UK). Sodium citrate, Tris, $o$-phthaldehyde (OPA), sodium dodecyl sulphate (SDS), ethylenediaminotetraacetic acid (EDTA), ethylene glycol tetraacetic acid (EGTA), ammonium persulfate (APS), tetrametilendiammina (TEMED), PUT, SPD, SPM, trichloroacetic acid (TCA), dithiothreitol (DTT), perchloric acid (PCA) and all reagents were from Sigma Chemicals (St Louis, MO, USA). Acetonitrile, tetrahydrofuran and all solvents were obtained from Mallinckrodt Baker (Milan, Italy).

\section{Extraction of anthocyanins and determination of total phenols}

The anthocyanin fraction (SE) was recovered from strawberry fruits (Fragaria $\times$ ananassa cv. Pajaro) commercially available on the market. Fruits were sorted to eliminate damaged, shrivelled, and unripe fruits, and selected for uniform size and colour. The fresh material ( $1 \mathrm{~g}$ of fresh fruit per $10 \mathrm{~mL}$ extraction solution) was extracted, under stirring for 1 hour (70\% ethanol and 30\% water both acidified with $\mathrm{HCOOH} \mathrm{1.8 \%}$ $\mathrm{v} / \mathrm{v}$, final $\mathrm{pH}$ of the mixture 2.8). The sample was filtered, the supernatant obtained from $10 \mathrm{~g}$ of fresh fruits was recovered, dried and redissolved in $1 \mathrm{~mL}$ of the extractive mixture, then analyzed by HPLC/DAD/MS. The total phenolic amount was measured by means of the Folin-Ciocalteu method ${ }^{62}$ using chlorogenic acid as standard, for which a calibration curve was prepared with solutions of $1,2,5,10$, and $20 \mu \mathrm{g} \mathrm{L}^{-1}$ of this compound ( $\left.y=0.0648 x-0.0106, R^{2}=0.9996\right)$.

\section{HPLC/DAD/MS analysis of the SE extract}

HP 1100 with a Diode Array Detector (DAD) and a mass detector HP 1100 MDS and interface API/ESI (Atmospheric Pressure Ionization - Electrospray) were all from Agilent Technologies. The operative conditions of the MS detector were: capillary voltage from 3000 to $3500 \mathrm{~V}$, working both in positive and negative ionization mode, with fragmentor values of $100 \mathrm{~V}$, $120 \mathrm{~V}, 150 \mathrm{~V}$ and $200 \mathrm{~V}$.

Column Sinergy Max RP-80A, $150 \times 3 \mathrm{~mm}, 4 \mu$, flow $0.4 \mathrm{~mL} \min ^{-1}$; multistep gradient elution with $\mathrm{A}: \mathrm{H}_{2} \mathrm{O} 95 \%$ and $\mathrm{HCOOH} 5 \%$; $\mathrm{B}: \mathrm{CH}_{3} \mathrm{CN} ; 95 \% \mathrm{~A}$ at time $0 ; 88 \% \mathrm{~A}$ after $8 \mathrm{~min}$; $85 \% \mathrm{~A}$ at $14 \mathrm{~min} ; 75 \% \mathrm{~A}$ at $26 \mathrm{~min} ; 55 \% \mathrm{~A}$ at $30 \mathrm{~min}$; finally
$5 \% \mathrm{~A}$ at $34 \mathrm{~min}$ with a final plateau of $2 \mathrm{~min}$. The quantitative determination was done by the use of two external standards: keracyanin at $520 \mathrm{~nm}$ with a five point calibration curve $\left(R^{2} 0.999\right)$ for the anthocyanins; caffeic acid at $330 \mathrm{~nm}$ by a five point calibration curve of $\left(R^{2} 1.0\right)$ for the cumaroyl glycosides.

\section{Cell culture}

A highly metastatic murine B16-F10 melanoma cell line was purchased from the Division of Cancer Treatment, Tumor Repository NIH (Frederick, MD). Cells were cultured in DMEM with $10 \%$ FCS, supplemented with $200 \mathrm{mM}$ glutamine, $100 \mathrm{U} \mathrm{mL}^{-1}$ penicillin/streptomycin, and maintained in a humidified atmosphere of $5 \% \mathrm{CO}_{2}$ at $37{ }^{\circ} \mathrm{C}$. For proliferation studies, cells were plated and grown in $35 \mathrm{~mm}$ dishes as reported above, and treated with SE (about $10 \mu \mathrm{M}$ anthocyanin content) for 24,48 and 72 hours. Cells were detached with EDTA and counted using a Neubauer modified chamber. Viability was assessed after Trypan Blue staining.

\section{Transglutaminase assay and polyamine detection}

Transglutaminase assay was performed in the presence of $\left[{ }^{14} \mathrm{C}\right]$-methylamine. Proteins were precipitated in $10 \%$ TCA, solubilised in $0.1 \mathrm{~N} \mathrm{NaOH}$ at $37{ }^{\circ} \mathrm{C}$ and the incorporation of radiolabelled methylamine into the protein was measured using a scintillation counter (Beckman LS-5000TD, CA, USA). The determination of polyamines in cell lysates was carried out using HPLC. Briefly, culture cell lysates were deproteinized with PCA, supernatants were derivatized with OPA and injected into the HPLC (AKTABASIC 10, Amersham Pharmacia Biotech., Milan, Italy). Reverse-phase separations were conducted at room temperature in a LC-18 Supelcosyl column $(150 \mathrm{~mm} \times$ $4.6 \mathrm{~mm}, 3 \mu \mathrm{m}$ ) (Supelco, Milan, Italy). The derivatives were separated on two mobile phases: A, 95\% $350 \mathrm{mM}$ sodium citrate, $\mathrm{pH} 4.0,5 \%$ tetrahydrofuran and B, 45\% $350 \mathrm{mM}$ sodium citrate, $\mathrm{pH} 4.0,40 \%$ acetonitrile, 15\% tetrahydrofuran. Elution consisted of a linear gradient from $50 \%$ to $100 \%$ of buffer B in $5 \mathrm{~min}$, then an isocratic elution for $15 \mathrm{~min}$, at a flow rate of $0.9 \mathrm{~mL} \mathrm{~min}^{-1}$. Detection was accomplished using a spectrofluorimeter (Jasco FP-1520; Easton, MD, USA). Fluorescence detection was set at $\lambda_{\mathrm{ex}} 330 \mathrm{~nm}$ and $\lambda_{\mathrm{em}} 445 \mathrm{~nm}$.

\section{Immunoblot analysis}

Total melanoma cell lysate extraction: briefly, cells were lysed in High Salt Buffer (50 mM Tris-HCl pH 7.5, $350 \mathrm{mM} \mathrm{NaCl,} 1 \mathrm{mM}$ $\mathrm{MgCl}_{2}, 0.5 \mathrm{mM}$ EDTA, $0.1 \mathrm{mM}$ EGTA) containing protease inhibitors. After addition of Nonidet P-40 to a final concentration of $1 \%$, the lysate was vigorously mixed for $15 \mathrm{~s}$, kept on ice for $30 \mathrm{~min}$ and then centrifuged at $1000 \times g$ for $15 \mathrm{~min}$ at $4{ }^{\circ} \mathrm{C}$. The resulting supernatant was stored at $-80{ }^{\circ} \mathrm{C}$ until use. Equal amounts of proteins extracted from B16-F10 cell lines (treated or untreated) were separated on 12\% SDS polyacrylamide gel and transferred to the immobilon membrane (Millipore) using a Bio-Rad electroblot apparatus. Membranes were incubated with rabbit anti- $\beta$-actin or mouse anti-p53 or rabbit anti-p21 antisera according to manufacturer's instructions. Immunoreactive bands were detected by chemilumineSEnce 
(SuperSignal reagent, Pierce) after incubation with peroxidaseconjugated secondary antibodies (Jackson Immunoresearch). Quantification analyses were performed using LAS3000 Imaging System (Fuji) and ImageQuant (Amersham Biosciences) software.

\section{Protein extraction}

Proteins were extracted from SE-treated B16-F10 cells according to the published method. ${ }^{8}$ Protein concentration was determined in the supernatants by Bradford protein assay (BioRad). Samples were stored at $-80{ }^{\circ} \mathrm{C}$ until use.

\section{D gel analysis}

For the first dimension of two-dimensional electrophoresis Amersham pH 3-10 NL immobilized pH gradient (IPG) strips were used to separate the cell proteins according to their isoelectric points as reported. ${ }^{8}$ The IPG strips were equilibrated as follows: (a) $6 \mathrm{M}$ urea, $30 \%$ glycerol, $2 \% \mathrm{SDS}, 0.002 \%$ bromophenol blue, $50 \mathrm{mM}$ Tris-HCl pH 8.0, 4.6 mM DTT were mixed for 30 min with shaking at room temperature; (b) $6 \mathrm{M}$ urea, $30 \%$ glycerol, $2 \%$ SDS, $0.002 \%$ bromophenol blue, $50 \mathrm{mM}$ Tris-HCl pH 8, $0.22 \mathrm{mM}$ iodoacetamide were mixed for $30 \mathrm{~min}$ on a shaker. The strips were rinsed with $\mathrm{MQ} \mathrm{H}_{2} \mathrm{O}$ and applied to the top of polyacrylamide slab gels, containing $41.7 \%$ acrylamide (12.5\%), 25\% Tris-HCl (0.5 M, pH 8.0), 1\% SDS (10\%), $1 \%$ APS (10\%), 0.034\% TEMED and 31.3\% $\mathrm{H}_{2} \mathrm{O}$. Strips and gel were put in the vertical slab electrophoresis unit (Hoefer SE 600 Ruby, Amersham Biosciences). Intensity of the spots was expressed as integrated optical density using Gel-Pro Analyzer software.

\section{Protein staining and analysis}

The gels were fixed in $100 \mathrm{~mL}$ of fixing solution (50\% ethanol, $12 \%$ acetic acid and $0.05 \%$ of $35 \%$ formaldehyde solution) and shaken overnight at room temperature. Proteins were stained by silver staining. Gels were scanned using a Duoscan AGFA scanner and kept under vacuum in $1 \%$ acid acetic solution. Analysis of the gels was made by the PD-Quest 2-D Analysis software (Biorad). Average gels from three independent experiments were compared to each other and spots differing at least fourfold in intensity were marked for further analysis.

\section{Protein digestion and MS analysis}

Spots from 2D-PAGE were excised and destained by adding $200 \mu \mathrm{l}$ of $1: 1$ solution of $30 \mathrm{mM}$ Potassium Ferricyanide and $100 \mathrm{mM}$ Sodium Thiosulfate at room temperature for $20 \mathrm{~min}$. Cysteines were subsequently reduced with $50 \mu \mathrm{l} 10 \mathrm{mM}$ DTT and alkylated with $50 \mu \mathrm{l}$ of $55 \mathrm{mM}$ iodoacetamide. ${ }^{63}$ After derivatization, the samples were incubated overnight at $37{ }^{\circ} \mathrm{C}$ with $20 \mu \mathrm{l}$ of a buffer solution, $50 \mathrm{mM}$ ammonium bicarbonate, containing sequence grade trypsin (Sigma) at $10 \mathrm{ng} \mathrm{\mu l}^{-1}$. To stop the reaction $3 \mu \mathrm{l}$ of $10 \%$ trifluoroacetic acid (TFA) were added. Following the digestion, the samples were used for protein identification by MALDI-TOF-MS and MS/MS analyses.

For the mass spectrometric analysis of tryptic digests, samples were prepared by reverse phase extraction using ZipTip $\mathrm{C}_{18}$ according to the manufacturer guidelines (Millipore, CA, USA). Elution was performed with a 50\% acetonitrile (ACN)/TFA $0.1 \%$ solution of $\alpha$-cyano-4-hydroxycinnamic acid at $3.6 \mathrm{mg} \mathrm{mL}^{-1}$ directly on the MTP Ground Steel 384 target (Bruker Daltonics). Thin layer protocol was followed for sample spotting. All MALDI-TOF-MS and MS/MS spectra were acquired on a UltraFlex III TOF/TOF mass spectrometer (Bruker Daltonics) in reflectron mode with voltages of 25.0, 21.7 for the first and second ion extraction stages and $9.0 \mathrm{kV}$ for the lens, $26.3 \mathrm{kV}$ for reflector $1,13.8 \mathrm{kV}$ for reflector 2 . The value of the laser power attenuator value was adjusted for each acquisition to balance differences in sample preparation. Quadratic external calibration of TOF was performed on the monoisotopic masses of the peptide calibration standard II mixture from bruker-daltonics containing Angiotensin II, Angiotensin I, Substance P, Bombesin, Renin Substrate, ACTH (1-17), ACTH (18-39) and Somatostatin. Monoisotopic peaks were selected for peptide fingerprinting using the FlexAnalysis 3.0 software (Bruker Daltonics). BioTools 3.0 was used to submit mass lists for protein identification. The research was conducted with the NCBI database. The query was unrestricted, the maximal tolerance for masses was $50 \mathrm{ppm}$ after an internal calibration using the autolysis product of trypsin, at most one miss-cleavage for tryptic digestion was allowed, and the modifications accepted were carboamidomethylation with iodoacetamide of cysteines and possible oxidation of methionines.

Peptide fragmentation experiments to confirm PMF identifications (for signals sufficiently intense) were performed on the same instrument working in LIFT mode.

Voltages were set as follows: 8.0, 7.2 for the first and second ion extraction stages and $3.6 \mathrm{kV}$ for the lens, $29.5 \mathrm{kV}$ for reflector $1,13.8 \mathrm{kV}$ for reflector $2,19.0 \mathrm{kV}$ for Lift 1 and 3.2 for Lift 2. Signals selected for fragmentation were chosen after the analysis of PMF results. FlexAnalysis 3.0 was used for spectra processing and BioTools 3.0 for search submissions. The query was restricted to mammalian proteins, the maximal tolerance for peptide masses was $50 \mathrm{ppm}$ and the maximal tolerance for MS/MS data was $0.3 \mathrm{Da}$. The remaining search parameters were set as for the PMF search.

\section{Statistical analysis}

Data shown represent mean \pm standard deviation (SD). Statistical analyses for detection of significant differences between the control and experimental groups were carried out using Student's $t$ test.

\section{Acknowledgements}

This contribution is following the 2013 Padova ItPA Congress.

\section{References}

1 F. L. Meyskens and E. Szabo, Cancer Epidemiol. Biomarkers Prev., 2005, 14, 1366-1369.

2 M. A. Lila, J. Biomed. Biotechnol., 2004, 5, 306-313.

3 K. R. Määtta, A. Kamal-Eldin and A. R. Törrönen, J. Agric. Food Chem., 2004, 52, 6178-6187.

4 Z. Juranić and Z. Žižak, BioFactors, 2005, 23, 207-211. 
5 A. Fait, K. Hanhineva, R. Beleggia, N. Dai, I. Rogachev, V. J. Nikiforova, A. R. Fernie and A. Aharoni, Plant Physiol., 2008, 148, 730-750.

6 S. J. Duthie, Mol. Nutr. Food Res., 2007, 51, 665-674.

7 M. Kahkonen, A. Hopia and M. Heinonen, J. Agric. Food Chem., 2001, 49, 4076-4082.

8 C. Forni, R. Braglia, A. Lentini, M. Nuccetelli, B. Provenzano, C. Tabolacci and S. Beninati, Amino Acids, 2009, 36, 731-738.

9 A. Lentini, C. Tabolacci, B. Provenzano, S. Rossi and S. Beninati, Plant Physiol. Biochem., 2010, 48, 627-633.

10 F. Lopes-da-Silva, M. T. Escribano-Bailòn, J. J. Pérez Alonso, J. C. Rivas-Gonzalo and C. Santos-Buelga, LWT-Food Sci. Technol., 2007, 40, 374-382.

11 A. Lentini, B. Provenzano, C. Tabolacci and S. Beninati, Amino Acids, 2009, 36, 701-708.

12 J. E. Folk, Annu. Rev. Biochem., 1980, 49, 517-531.

13 S. Beninati and M. Piacentini, Amino Acids, 2004, 26, 367-372.

14 G. Di Giacomo, A. Lentini, S. Beninati, M. Piacentini and C. Rodolfo, Amino Acids, 2009, 36, 717-724.

15 C. Tabolacci, A. Lentini, B. Provenzano and S. Beninati, Amino Acids, 2012, 42, 975-986.

16 N. Almog and V. Rotter, Biochim. Biophys. Acta, 1997, 1333, 1-27.

17 A. H. Stegh, Expert Opin. Ther. Targets, 2012, 16, 67-83.

18 T. Abbas and A. Dutta, Nat. Rev. Cancer, 2009, 9, 400-414.

19 N. P. Seeram, L. S. Adams, Y. Zhang, R. Lee, D. Sand, H. S. Scheuller and D. Heber, J. Agric. Food Chem., 2006, 54, 9329-9339.

20 Y. Zhang, N. P. Seeram, R. Lee, L. Feng and D. Heber, J. Agric. Food Chem., 2008, 56, 670-675.

21 N. P. Seeram, L. S. Adams, M. L. Hardy and D. Heber, J. Agric. Food Chem., 2004, 52, 2512-2517.

22 M. Shynu, P. K. Gupta and M. Saini, Recent Pat. Biotechnol., 2011, 5, 85-94.

23 M. E. Olsson, J. Ekvall, K. Gustavsson, J. Nilsson, D. Pillai, I. Sjoholm, U. Svensson, B. Akesson and M. G. L. Nyman, J. Agric. Food Chem., 2004, 52, 2490-2498.

24 P. Mattila and J. Kumpulainen, J. Agric. Food Chem., 2002, 50, 3660-3667.

25 P. N. Chen, S. C. Chu, H. L. Chiou, W. H. Kuo, C. L. Chiang and Y. S. Hsieh, Cancer Lett., 2006, 235, 248-259.

26 F. A. M. Silva, F. Borges, C. Guimaraes, J. L. F. C. Lima, C. Matos and S. Reis, J. Agric. Food Chem., 2000, 48, 2122-2126.

27 A. A. Nystrom, K. H. Schmitz, C. L. Perry, L. A. Lytle and D. Neumark-Sztainer, Prev. Med., 2005, 40, 203-208.

28 L. R. Ferguson, Z. Shuo-tun and P. H. Harris, Mol. Nutr. Food Res., 2005, 49, 585-693.

29 K. Kikugawa, T. Hakamada, M. Hasunuma and T. Kurechi, J. Agric. Food Chem., 1983, 1, 780-785.

$30 \mathrm{~J}$. Estaquier, F. Vallette, J. L. Vayssiere and B. Mignotte, Adv. Exp. Med. Biol., 2012, 942, 157-183.

31 N. C. Reich, M. Oren and A. J. Levine, Mol. Cell. Biol., 1983, 3, 2143-2150.

32 W. C. Weinberg, C. G. Azzoli, K. Chapman, A. J. Levine and S. H. Yuspa, Oncogene, 1995, 10, 2271-2279.
33 J. Tucholski, Amino Acids, 2010, 39, 523-532.

34 S. Mishra and L. J. Murphy, Biochem. Biophys. Res. Commun., 2006, 339, 726-730.

35 W. S. El-Deiry, T. Tokino, V. E. Velculescu, D. B. Levy, R. Parsons, J. M. Trent, D. Lin, W. E. Mercer, K. W. Kinzler and B. Vogelstein, Cell, 1993, 75, 817-825.

36 Y. Xiong, G. J. Hannon, H. Zhang, D. Casso, R. Kobayashi and D. Beach, Nature, 1993, 366, 701-704.

37 F. T. Liu and G. A. Rabinovich, Nat. Rev. Cancer, 2005, 5, 29-41.

38 D. Demydenko and I. Berest, Exp. Oncol., 2009, 31, 74-79.

39 N. Rubinstein, M. Alvarez, N. W. Zwirner, M. A. Toscano, J. M. Ilarregui, A. Bravo, J. Mordoh, L. Fainboim, O. L. Podhajcer and G. A. Rabinovich, Cancer Cell, 2004, 5, 241-251.

40 I. Camby, M. Le Mercier, F. Lefranc and R. Kiss, Glycobiology, 2006, 16, 137R-157R.

41 K. L. Rock, C. Gramm, L. Rothstein, K. Clark, R. Stein, L. Dick, D. Hwang and A. L. Goldberg, Cell, 1994, 78, 761-771.

42 C. Montagut, A. Rovira and J. Albanell, Clin. Transl. Oncol., 2006, 8, 313-317.

43 M. Rechsteiner and C. P. Hill, Trends Cell Biol., 2005, 15, 27-33.

44 I. Mao, J. Liu, X. Li and H. Luo, Cell Mol. Life Sci., 2008, 65, 3971-3980.

45 A. Dreiseitel, P. Schreier, A. Oehme, S. Locher, G. Rogler, H. Piberger, G. Hajak and P. G. Sand, Biochem. Biophys. Res. Commun., 2008, 372, 57-61.

46 N. Yamamoto, H. Sawada, Y. Izumi, T. Kume, H. Katsuki, S. Shimohama and A. Akaike, J. Biol. Chem., 2007, 282, 4364-4372.

47 F. Rondepierre, B. Bouchon, J. Papon, M. Bonnet-Duquennoy, R. Kintossou, N. Moins, J. Maublant, J. C. Madelmont, M. D'Incan and F. Degoul, Biochim. Biophys. Acta, 2009, 1794, 61-69.

48 H. G. Huddleston, K. K. Wong, W. R. Welch, R. S. Berkowitz and S. C. Mok, Gynecol. Oncol., 2005, 96, 77-83.

49 J. Joseph, A. Cardesa and J. Carreras, Br. J. Cancer, 1997, 76, 600-605.

50 S. Patra, A. Ghosh, S. S. Roy, S. Bera, M. Das, D. Talukdar, S. Ray, T. Wallimann and M. Ray, Amino Acids, 2012, 42, 2319-2330.

51 M. Upadhyay, J. Samal, M. Kandpal, O. V. Singh and P. Vivekanandan, Pharmacol. Ther., 2013, 137, 318-330.

52 S. E. Old, L. E. Landa and H. W. Mohrenweiser, Mol. Cell. Biochem., 1989, 89, 73-85.

53 Y. Wang, Y. Lu, J. Yang, Y. Shi, M. Lan, Z. Liu, H. Zhai and D. Fan, J. Cancer Res. Clin. Oncol., 2008, 34, 995-1003.

54 S. C. Kalhan and R. W. Hanson, J. Biol. Chem., 2012, 287, 19786-19791.

55 J. W. Locasale, A. R. Grassian, T. Melman, C. A. Lyssiotis, K. R. Mattaini, A. J. Bass, G. Heffron, C. M. Metallo, T. Muranen, H. Sharfi, A. T. Sasaki, D. Anastasiou, E. Mullarky, N. I. Vokes, M. Sasaki, R. Beroukhim, G. Stephanopoulos, A. H. Ligon, M. Meyerson, 
A. L. Richardson, L. Chin, G. Wagner, J. M. Asara, J. S. Brugge, L. C. Cantley and M. G. Vander Heiden, Nat. Genet., 2011, 43, 869-874.

56 A. Carracedo, L. C. Cantley and P. P. Pandolfi, Nat. Rev. Cancer, 2013, 13, 227-232.

57 R. Scatena, P. Bottoni, A. Pontoglio, L. Mastrototaro and B. Giardina, Expert Opin. Invest. Drugs, 2008, 17, 1533-1545.

58 G. Williamson and C. Manach, Am. J. Clin. Nutr., 2005, 81, 243S-255S.
59 S. Passamonti, U. Vrhovsek, A. Vanzo and F. Mattivi, FEBS Lett., 2003, 544, 210-213.

60 V. Nicolin, V. Grill, F. Micali, P. Narducci and S. Passamonti, J. Mol. Histol., 2005, 36, 45-50.

61 A. Lentini, C. Tabolacci, P. Mattioli, B. Provenzano and S. Beninati, Cancer Biother. Radiopharm., 2010, 25, 497-503.

62 F. L. Booker and J. E. Miller, J. Exp. Bot., 1998, 49, 1191-1202.

63 A. Shevchenko, M. Wilm, O. Vorm and M. Mann, Anal. Chem., 1996, 68, 850-858. 